\title{
Towards better representation of organic agriculture in life cycle assessment
}

\author{
Hayo M G van der Werf ${ }^{1 *}$, Marie Trydeman Knudsen², Christel Cederberg ${ }^{3}$
}

${ }^{I}$ SAS, INRAE, Agrocampus Ouest, Rennes, France; ${ }^{2}$ Dept. of Agroecology, Aarhus University, Tjele, Denmark; ${ }^{3}$ Division Physical Resource Theory, Chalmers University of Technology, Gothenburg, Sweden

*Corresponding author, e-mail: hayo.van-der-werf@inrae.fr

\section{Preface}

The environmental effects of agriculture and food are much discussed, with competing claims concerning the impacts of conventional and organic farming. Life cycle assessment (LCA) is the method most widely used to assess environmental impacts of agricultural products. Current LCA methodology and studies tend to favour high-input intensive agricultural systems and misrepresent less intensive agroecological systems such as organic agriculture. LCA assesses agroecological systems inadequately for three reasons: i) a lack of operational indicators for three key environmental issues, ii) a narrow perspective on functions of agricultural systems and iii) inconsistent modelling of indirect effects.

\section{Abstract}

Societal interest in the environmental performance of agricultural systems and their products is great and growing. Life cycle assessment (LCA) is the method most widely used to analyse environmental impacts of agricultural products. Current LCA methodology and studies tend to favour high-input intensive agricultural systems and misrepresent less intensive agroecological systems such as organic agriculture. This is due partly to LCA's product-based approach, which focuses on the production of biomass, without considering other ecosystem services from agricultural systems, and partly because LCA rarely considers aspects that agroecology aims to improve (soil health, biodiversity status, pesticide use impacts). The current practice of limiting consideration of indirect effects in LCA studies to indirect land use change, using economic models that ignore drivers of societal change and effects of policy instruments, further favours intensive agricultural systems. We identify three key areas (additional indicators, broader perspective, indirect effects) for which we propose recommendations and priorities for research on environmental assessment of agricultural systems.

\section{Introduction}

Societal interest in sustainable agriculture and food is great and growing ${ }^{1,2}$, leading to a demand for information about the environmental performance of agricultural systems, food products and overall food 
chains from almost all parts of society: policy makers, farmers, agribusinesses, public procurers, the media and consumers. From this diverse group of stakeholders, different questions arise, such as: 'Is product A better or worse for the environment than product B? Does converting to this production system really decrease environmental impacts? Should this innovative management technology be encouraged from an environmental perspective?'

The method most widely used to answer such questions is life cycle assessment (LCA), whose use is now well established for assessing resource depletion issues and environmental and health impacts caused by production of agricultural products. LCA's basic principle ${ }^{3}$ is to follow a product through its life cycle, defining a boundary between its 'product system' (the 'technosphere') and the surrounding environment. Energy and material flows crossing this boundary are related to the system's inputs (e.g. resources) and outputs (e.g. emissions to water and air). Resource consumption and pollutant emissions are then aggregated into impact indicators; LCA thus focuses on negative impacts rather than including positive impacts. The first LCAs were performed in the 1970 s by Coca-Cola ${ }^{\circledR}$ when it investigated consequences of switching from glass bottles to plastic bottles ${ }^{4}$. In the 1990s, application of LCA to agricultural systems began. From 1992 to 2018, the number of peer-reviewed English-language articles using LCA to assess agri-food systems increased from 1 to 1040 per year (Fig. 1). Today, LCA is the core method in the European Union (EU)'s development of a harmonised methodology for calculating environmental footprints of products (PEF) including several food groups 5 .

LCAs of agricultural products very often consider only one function of an agricultural system: provision and processing of biomass to produce food, fibre or bioenergy ${ }^{6}$. By representing agricultural systems in a limited manner, this product-based approach strongly contrasts with conceptual frameworks that focus on the multifunctionality of agriculture and its provision of a broad range of ecosystem services ${ }^{7}$ (contributions that ecosystems make to human well-being). The ecosystem services concept has gained increasing global recognition in policy making over the last decade, and today it is a significant research topic with diverse modelling and mapping approaches at multiple spatial and temporal scales ${ }^{8}$. Another example of a wider view of agriculture is the concept of agroecology (Fig 2), recognised by United Nations (UN) institutions as a science and social movement in the transition to sustainable food systems and a pathway to achieving the UN's Sustainable Development Goals (SDGs) ${ }^{9}$. Organic agriculture includes many agroecological practices; its umbrella organisation, IFOAM - Organics International, defines it as a 'production system that sustains the health of soils, ecosystems and people' and 'relies on ecological processes, biodiversity and cycles adapted to local conditions', ultimately basing it on four principles: health, ecology, fairness and care ${ }^{10}$.

Willet et al. ${ }^{1}$ highlight the urgency of transforming global food systems to meet the SDGs and the UN's Paris climate agreement; they propose planetary boundaries for six key Earth system processes (climate change, 
land-system change, freshwater use, nitrogen and phosphorous cycling, and biodiversity losses) on which food production and consumption have great impact. There is growing agreement on the need for changes in agri-food systems to make progress towards SDGs. Willet et al. ' even call for a 'Great Food Transformation', which would require appropriate assessment tools and methods to examine the environmental performance of agriculture.

Here, we identify important deficiencies in LCA methodology when assessing agriculture based on agroecological principles, with examples of applying it to organic agriculture. We propose ways to strengthen the ability of LCA to capture environmental impacts of contrasting farming systems adequately.

\section{Consequences of limiting agricultural system representation}

LCA has a narrow perspective on functions of agriculture, linked to its product-based approach.

\section{Narrow perspective on functions of agriculture}

When analysing an agricultural system, LCA assesses its environmental impacts by considering both on-site and off-site (associated with inputs) resource use, pollutant emissions and land use. LCA can capture resource use and certain impacts (Fig. 3), although biodiversity losses and toxicity impacts due to pesticide use are rarely included, as discussed later. Impacts are quantified using a set of indicators and reported per unit of product (e.g. $\mathrm{kg}$ of milk or wheat); consequently, they assess eco-efficiency ${ }^{11}$. In contrast, the ecosystem services framework ${ }^{7}$ models an agricultural system differently, considering the landscape of the entire farm or farming region including its semi-natural habitats such as hedges, field margins, water bodies and forests. Ecosystem services are generally expressed per unit area (e.g. ha of land ${ }^{12}$ ). This framework considers the supply of a broad range of services (Fig. 3) from the agricultural system: provisioning (e.g. crops, livestock, water), regulating and maintenance (e.g. pest control, pollination, climate regulation) and cultural (e.g. recreation, education), as well as regulating and maintenance services supplied by other ecosystems to the agricultural system. However, environmental impacts associated with inputs used in the agricultural system are not considered.

The frameworks of LCA and ecosystem services assessment differ greatly in how they consider land. In LCA, land is an elementary resource flow modelled in the same way as fossil energy and ore resources ${ }^{3}$, while in ecosystem services assessment, it is part of the agricultural system, as land is the basis for essential ecosystem functions, many of which are inextricably intertwined with the soil and its functions. Furthermore, LCA considers only the provision of biomass (e.g. crops, animals) from the agricultural system. With this narrow focus, LCA faces obvious problems when assessing multifunctional agricultural systems, such as organic agriculture, and other food systems developed within the concept of agroecology. In the scientific literature, there have been many attempts to set out principles of agroecology, and a UN expert panel has 
recently suggested a comprehensive set of 13 agroecological principles. These are organised around three operational principles for sustainable food systems: i) improve resource efficiency (recycling; input reduction); ii) strengthen resilience (soil health; animal health and welfare; biodiversity; synergy; economic

112 diversification) and iii) secure social equity/responsibility (co-creation of knowledge; social values and diets;

113 fairness; connectivity; land and natural resource governance; participation) ${ }^{9}$. Current LCA methods assess the 114 two resource efficiency principles sufficiently but consider inadequately many of the agroecological principles designed to strengthen the resilience of food systems. This further illustrates the limited perspective that LCA provides on food systems.

\section{Product-based approach}

119 There is a large consensus that organic agriculture has lower environmental impacts per unit of land occupied 120 than conventional agriculture ${ }^{13,14}$. If a farming region shifts to organic agriculture, its environmental impacts 121 will decrease (e.g. biodiversity will increase), and pesticide contamination of soil, water, air and food will 122 largely cease ${ }^{2}$. Thus, government policies often favour a shift from conventional to organic agriculture. From 123 an LCA viewpoint, however, organic agriculture is not an obvious answer to environmental problems of 124 conventional agriculture, because LCA defines the function of the studied system using a "functional unit", 125 which should be a precise measure of what the system delivers. Because LCAs express impacts per unit of product by default, they typically identify the solutions that reduce emissions per unit of product as being the best for production systems. Although organic agriculture generally emits less pollutants per unit of land occupied than conventional agriculture (an area-based approach), it may have higher impacts per unit of product (e.g. land occupation, eutrophication, acidification) ${ }^{13,14}$, due to its lower yields per unit area. Thus, focussing solely on impacts per unit of product may well result in decisions in favour of conventional agriculture that may increase pollutant emissions in the farming region.

Furthermore, many consumers perceive organic food to be of higher quality in terms of nutritional quality, pesticide residues and ethics, such as animal welfare ${ }^{15}$. Studies confirm organic products' better nutritional quality ${ }^{16}$ and positive effects on pesticide residues in urine ${ }^{17}$ and animal welfare ${ }^{18}$. By expressing impacts per unit of product, however, LCA studies comparing organic and conventional food rarely consider product quality, ignoring key qualitative aspects that are recognised in the principles of organic agriculture.

\section{Neglected environmental issues}

140 Surprisingly, LCA studies of agriculture and food systems rarely consider important issues such as land 141 degradation, biodiversity losses, pesticide effects and animal welfare. The last item is not strictly an 142 environmental issue, but it has recently been proposed as a fourth pillar of life cycle sustainability 143 assessment ${ }^{19}$. Although animal welfare is important, and subject to trade-offs with environmental efficiency, we will not address it here. 
147 Land degradation is a serious and widespread problem, including soil-deteriorating processes such as erosion,

148 compaction, salinisation and soil organic carbon losses. Unsustainable land management in agriculture is a

149 dominant driver of land degradation ${ }^{20}$.

151 Despite efforts over the last 15 years to improve assessment of impacts due to land use, soil properties and functions remain little represented in LCA, as discussed by Vidal Legaz and colleagues when evaluating models assessing impacts on soil quality ${ }^{21}$. The models were evaluated against criteria such as scientific soundness, stakeholder acceptance, reproducibility and model applicability in LCA. The authors conclude that none of the models fulfilled all of the criteria, and that trade-offs were most frequent between the relevance of the impact processes modelled and the model's applicability. Of the models assessed, the LANCA model was recommended for assessing land use impact in the EU PEF framework, but when recently tested, it was found to still have some important limitations ${ }^{22}$. One main drawback of LANCA is that it provides land use impact indicators at the coarse country scale, while soil properties have high spatial variability and potential negative impacts are influenced greatly by local conditions. To favour assessment of soil quality in LCA, methods need further development to strike a better balance between consideration of local conditions and applicability.

A meta-analysis of 56 studies comparing a set of soil quality indicators measured in conventional and organic systems shows that organic farming methods have a strong positive effect on total microbial abundance and activity in agricultural soils ${ }^{23}$. According to its definition, organic agriculture must sustain and enhance soil fertility, which is considered an important output of the farming system. In most agri-food LCA studies, information about human pressure on land is expressed using the simple indicator 'area of land use per functional unit and year'. Thus, soil quality effects of land management practices central to organic agriculture - such as diversifying crop rotations and using intercrops and catch crops - are largely ignored. Consequently, current LCA studies rarely capture positive characteristics of these practices that are core elements of organic agriculture.

The extent to which LCA tends to ignore impacts on soil quality can be illustrated by the fact that PestLCI ${ }^{24}$, the state-of-the-art simulation model used in LCA studies to estimate pesticide emissions from an agricultural field to air, surface water and ground water, considers soil to be part of the technosphere. Thus, in this reductive viewpoint, the soil is equivalent to other technosphere elements such as factories, electrical power stations and livestock buildings. Lumping soil into the technosphere precludes assessing the toxicity of pesticide residues on soil life in LCAs, which is an obvious deficiency, as the presence of pesticide residues in conventional agricultural soils is the rule rather than the exception ${ }^{25}$. 
183 Despite repeated warnings about the rapid loss of biodiversity and mounting evidence of biodiversity's key

184 role in food security and nutrition, the ecosystems, species and within-species genetic resources of agricultural systems worldwide are becoming ever less diverse ${ }^{26}$. Since agriculture occupies more than onethird of global land area, biodiversity losses on agricultural land are crucial. Even though intensive agriculture is a main driver of certain trends in biodiversity (e.g. insect decline ${ }^{27}$ ), LCA studies of agricultural systems tend to ignore biodiversity impacts. Recent reviews of LCA studies of livestock systems ${ }^{28}(\mathrm{n}=173)$ and edible oils ${ }^{29}(\mathrm{n}=34)$ reveal that less than $5 \%$ of the studies considered biodiversity impacts. Even more striking, only $12 \%$ of LCA studies comparing conventional and organic agriculture considered biodiversity impacts $^{14}$.

Meta-analysis of many field observations has shown that organic agriculture supports biodiversity levels, measured as species richness, that are approximately $30 \%$ higher than those of conventional agriculture, a result that has remained robust over the last 30 years ${ }^{30}$. Even future LCA studies are unlikely to capture such large differences due to agricultural practices, as the method selected by the LCA community ${ }^{31}$ to assess impacts on biodiversity (potential species loss from land use) is recommended only for identifying hotspots within product systems, not for comparing products or production systems. This model thus cannot be used to distinguish conventional and organic agriculture. The latest version of this model distinguishes three levels of land use intensity ${ }^{32}$. A few studies (e.g. Knudsen et al. ${ }^{33}$ ) provide metrics to differentiate impacts of organic and conventional agriculture on biodiversity; however, an LCA-compatible method that can consider, in detail, impacts of the variety of agricultural practices on biodiversity in both conventional and organic agriculture is still lacking.

\section{Pesticide effects}

206 Worldwide, pesticide use increased from 1.5 to $2.6 \mathrm{~kg}$ active ingredient per ha of cropland from 1990 to $2015^{34}$. Pesticides are now recognised as a major driver of biodiversity $\operatorname{loss}^{26,27}$ in terrestrial and aquatic ecosystems, and can impact human health (e.g. cancer, neurological disease) ${ }^{35}$. They have caused deaths from acute poisoning ${ }^{36}$, especially in developing countries, and high pesticide exposure of rural populations in intensive farming regions has been observed in Argentina ${ }^{37}$. In many EU countries, reducing and 211 improving pesticide use to improve water quality are important policy actions, but reports of contamination 212 of surface and ground water by agrochemicals are numerous ${ }^{38,39}$. Despite the negative impacts that pesticides 213 can have on humans and ecosystems, agri-food LCA studies rarely consider them. For instance, ecotoxicity 214 was considered in only $14 \%$ of 173 LCA studies of livestock systems ${ }^{28}$, and toxicity-related impacts were considered in only $26 \%$ of 34 studies comparing organic and conventional agriculture ${ }^{14}$. can be considered an application of the precautionary principle. Attempts by LCA methodology to assess 
potential environmental and health impacts of pesticide use are laudable, but experience suggests that it may take 20-30 years to discover toxicological hazards of new pesticides that had seemed relatively harmless at first. For instance, when introduced in the 1970s, glyphosate-based herbicides were considered not to persist in the environment and to pose low risk to non-target species. Currently, however, glyphosate has been found to be widely present in the environment, probably carcinogenic to humans and a suspected endocrine disruptor $^{40}$. Similarly, when introduced in the 1980s, neonicotinoid insecticides were considered to have less environmental impact than the insecticides they replaced, due to the low doses used and their targeted applications, such as in seed coatings. It has recently emerged, however, that neonicotinoids accumulate in soils and have significant sublethal impacts on pollinators ${ }^{41}$. Furthermore, as time passes, previously unknown hazards associated with pesticides are discovered, such as endocrine disruption ${ }^{42}$ or impacts on child neurodevelopment ${ }^{43}$. Consequently, as fuller understanding of environmental and health impacts of pesticides may take several decades, these impacts tend to be underestimated. Furthermore, assessing toxicity effects in LCAs is also limited by the lack of toxicity data for some synthetic pesticides used in conventional agriculture and for some of the biological/natural and inorganic pesticides used in organic agriculture $^{14}$. Thus, LCA-based comparisons of toxicity effects of conventional and organic agriculture remain highly uncertain.

Tukker $^{44}$ describes the underlying evaluative philosophy of LCA as a risk assessment frame, based on the belief that knowledge about emissions and effects of substances on humans and ecosystems is adequate, that emission control will work and that nature is resilient. He contrasts the risk assessment frame to a precautionary frame, which reflects low trust in the adequacy of knowledge and in measures to control emissions, and the belief that nature is fragile. Tukker proposes an LCA approach based on the precautionary frame, involving indicators of the potential degree of ignorance, and the level of irreversibility of contamination and effects. These indicators would be used to give a bonus/penalty score to the emission and fate/effect elements that are used to calculate impacts in the traditional way. This approach may allow for implementation of the precautionary principle when assessing pesticide impacts, as knowledge about

\section{Including indirect effects of shifting to agroecological systems}

Attributional LCA provides information about impacts of the processes that are directly associated with a product's life cycle. In contrast, consequential LCA (CLCA) considers consequences of changes in the level of output of a product, including indirect effects outside the product life cycle ${ }^{45}$. CLCA commonly relies on economic models to capture relationships between demand for inputs, price elasticities, supply, etc. ${ }^{46}$, but it may also use simpler biophysical models ${ }^{47}$. Indirect land use change (ILUC) is the indirect effect considered most often in agri-food CLCAs to date, especially when studying crop-based biofuels ${ }^{48}$. Estimates of greenhouse gas (GHG) emissions due to ILUC vary widely, reflecting the high uncertainty of these models ${ }^{47}$. 
Analogous to the inclusion of ILUC GHG emissions in LCAs and carbon footprint studies of biofuels, a recent LCA study assigned additional GHG emissions to organic food production, referring to consequences of organic agriculture's need for more land to make up for lower yields ${ }^{51}$. Similarly, Searchinger et al. ${ }^{52}$ defined a 'carbon opportunity cost' as the amount of carbon that would be sequestered if the additional land used for organic agriculture were instead subject to natural revegetation. The justification for assigning additional GHG emissions to organic food resembles the reasoning in favour of 'land sparing': by adopting high-yield farming systems, we spare land for nature ${ }^{53}$. Obviously, if a farmer adopts practices that increase yields, less land will be needed to produce a given amount of agricultural goods. However, the land use dynamics associated with shifts between higher- and lower-yielding systems are less clear. Yield gains due to intensification may well increase profit in that area, thereby encouraging expansion. Therefore, land use intensification may coincide with expansion of agricultural land $^{54}$. Furthermore, it is far from certain that deforestation will slow down due to higher yields or that farmers will leave their land to revegetate naturally in areas where agriculture is economically challenging. Instead, they may, for instance, maintain extensive pasture operations in anticipation of more favourable economic conditions.

The understanding of cause-effect mechanisms of land use transitions needs to be improved. Some empirical knowledge exists about how agricultural land use patterns are affected by intensification or the introduction of biofuel crops. However, there is a lack of knowledge about land use consequences of agroecological foodsystem transitions, which involve changes in both production modes and consumption patterns. Consequently, cause-effect mechanisms for these transitions are even more uncertain and difficult to model. Further, economic models used in many CLCAs are calibrated using historical experiences and are ill suited for exploring situations in which public policies shape development towards compatibility with the Paris climate agreement and SDGs, which require drastic deviation from long-term trends, possibly through disruptive innovations that make established production practices obsolete.

Furthermore, a scientifically robust assessment of indirect effects cannot be limited to the (arbitrarily chosen) issue of land use change ${ }^{49}$, as other indirect effects are also likely to occur in the food system. A deficiency in models used in CLCA lies in their roots in neoclassical economics, which assumes that individuals have rational expectations and maximise utility $^{46}$ and excludes drivers of societal change such as ethical considerations. Taking meat as an example, it is difficult, if not impossible, to foresee the overall consequences in the food system of a shift in consumer demand towards more organic meat at the expense of conventional meat. Animal welfare is a major ethical attribute of organic food that influences European consumers' purchase decisions ${ }^{19}$. Such considerations may mean that consumers of organic food will purchase fewer animal-based food products but with higher (ethical) standards. Hardly any studies of such consumer behaviour exist; the few found (e.g. Baudry et al. ${ }^{55}$ ) show that consumers of organic food tend to eat less animal-based food and more plant-based food. Also, price effects must be included: if consumers buy 
organic products, which are more expensive than their non-organic equivalents, they will have less money to 294 buy other polluting products or services. Such effects are difficult and uncertain to quantify and have been included in very few food LCA studies ${ }^{56}$.

To summarise, approaches that assign additional GHG emissions to organic food products, due to lower yields than those of conventional food products, can be considered a way to integrate an environmental concern into LCA, in line with the precautionary principle. However, translating yield differences at any location into a corresponding area of natural land spared from conversion (or agricultural land available for revegetation) implies an oversimplification that does not capture the complexity of geographically diverse agroecological food systems. Singling out only one indirect effect when comparing farming systems and food products is a poor strategy when searching for the changes required to make progress on several SDGs. Furthermore, these approaches favour high-yielding intensive systems, which generally have high impacts per ha for a range of environmental concerns, thus strengthening the already narrow focus of LCA on provision of crop and animal products.

\section{Possible ways forward}

Meeting the SDGs requires urgent transformation of global agricultural and food systems towards agroecology. Doing so requires appropriate assessment tools and methods to examine the environmental performance of agricultural systems. By misrepresenting agroecological systems such as organic agriculture, current LCA studies tend to favour intensive agricultural systems that produce high yields but provide fewer ecosystem services overall than less intensive systems ${ }^{57}$. LCA assesses agroecological systems inadequately for three reasons: i) a lack of operational indicators for three key environmental issues, ii) a narrow perspective on functions of agricultural systems and iii) inconsistent modelling of indirect effects. Thus, we propose recommendations and priorities for three key areas of research on environmental assessment of agricultural systems. Recommendations for LCA practitioners assessing agricultural systems are summarised in Box 1.

\section{1) Additional indicators}

Land degradation represents one of the most urgent challenges for humanity ${ }^{20}$. In the planetary boundary framework, recently used to identify healthy diets and sustainable food production for the $21^{\text {st }}$ century ${ }^{1}$, soil quality impacts are not considered. We call for a boundary for land degradation to be added to this framework. The current modelling approach in LCA, in which soils are considered mainly as part of the technosphere, thus making them equivalent to replaceable capital stocks, is inadequate. The degree to which erosion, compaction, salinisation and loss of organic matter degrade soils, and the influence of agricultural practices on these disturbances, is crucial information that urgently needs to be included in LCAs and other frameworks for analysing agri-food systems. Methodological developments in this field should be a top research priority to improve consideration of soil quality in environmental assessments ${ }^{58}$. 
331 The alarming decline in biodiversity is a major environmental challenge for food production, as changes in 332 land and sea use are its most important drivers ${ }^{26}$. The limited degree to which agri-food LCA studies have 333 addressed biodiversity impacts to date is problematic, and an LCA-compatible biodiversity indicator 334 framework that can differentiate farm management practices at a fine scale is lacking. Consequently, systems 335 appear more favourable in environmental assessments as their land use decreases, even though they may 336 intensively use agrochemicals detrimental to biodiversity dimensions such as insect diversity ${ }^{27}$. Ignoring 337 important intensive practices (e.g. widespread pesticide use, low crop diversity) when assessing biodiversity 338 impacts is not consistent with recent research identifying drivers of species decline $e^{27,59}$ and can lead to the 339 conclusion that land sparing is the best solution for halting biodiversity losses associated with agriculture. 340 For instance, Willet et al. ${ }^{1}$ proposed a boundary for cropland use in future food systems without adequately 341 discussing land use intensity. There is a critical need for datasets and indicators to explicitly assess impacts 342 of farm management practices on biodiversity in environmental assessments of food and other agricultural 343 products $^{26}$.

Comprehensive assessment of pesticides' negative effects on ecosystems and humans requires detailed data on amounts and characteristics of active ingredients used, application methods, crop types and development stages, soil properties and climate conditions. Many of these data are insufficiently available in developed countries and often lacking in many developing countries. Likewise, the dearth of information on risks to farm workers' health due to working with pesticides is troublesome. While new pesticides often - but not always - tend to have lower impacts than existing pesticides, their full range of impacts requires decades to emerge, illustrating that knowledge about pesticide emissions, fate and effects is incomplete. Development of an approach based on the precautionary frame seems an appropriate way forward. Agri-food LCA studies are not alone in largely disregarding pesticide impacts; for instance, Willet et al. ${ }^{1}$ omitted them when choosing environmental indicators for guiding transformation of food systems. Given the many negative effects pesticides have on humans and nature, this omission is worrying, and reveals the need for massive and broad research to improve assessment of pesticides' environmental and health impacts.

Land degradation, biodiversity impacts and negative effects of pesticides are serious problems associated with agricultural production. LCA studies have rarely considered these detrimental processes to date, and LCA still lacks fully comprehensive indicators to quantify them when assessing food systems' environmental impacts. Consequently, decision makers are currently provided unbalanced information, as trade-offs among different environmental aspects are not sufficiently emphasised, leading to the obvious risk that environmental assessments of food systems will fail to detect synergies in land management options.

\section{2) The broader perspective}

Because LCA was originally developed to assess environmental impacts of industrial products, it focuses on 
reduced impacts per unit of product. When applied to agriculture, this approach tends to favour more intensive systems, which have higher yields but also higher impacts per unit area. Thus, LCA studies of agriculture and food implicitly advocate the land-sparing theory. This strong product-based approach, however, fits poorly when assessing impacts on important ecosystem services that must be managed at the landscape scale. For instance, mosaic landscapes with small fields and high crop diversity favour biodiversity and key ecosystem services (e.g. crop pollination, biological pest control) while maintaining agricultural productivity ${ }^{59}$, but current LCA practice does not capture the positive effects of these landscape configurations.

Furthermore, adequate assessment of agroecological systems, which are much more reliant on local resources and adapted to the local context than intensive high-external-input systems, requires a fine-grained approach to LCA that considers local soil, climate and ecosystem characteristics, as well as detailed representation of farm management practices. These variables should be integrated in models used to create LCA data. Current efforts to regionalise these data are a step in the right direction, but they need to be advanced to be able to assess agroecological systems at the necessary local spatial scale.

Measuring and valuing provision of ecosystem services for a range of spatial scales is a key area of innovation required to assess sustainability of food systems ${ }^{9}$. As current LCA methodology is not adequate to assess multifunctional agricultural systems with their surrounding landscapes, we propose to integrate it with other environmental assessment frameworks, such as that for ecosystem services. One example of such integration is the framework recently developed by Alejandre et al.$^{60}$ for optimal coverage of ecosystem services in LCA. The authors first propose a set of 15 categories of ecosystem services derived from the CICES classification method that provide optimal coverage. They then identify which of these categories are assessed in the widely used ReCiPe2016 LCA method. They finally prioritize missing categories, resulting in a ranking of ecosystem service categories to be included in LCA, to help guide the research community.

Overall performance of agricultural systems is complex to measure and model. Because most ecosystem services associated with agricultural production depend on the context (mostly at the farm and/or landscape

\section{3) Indirect effects}

Analysing and comparing contrasting farming systems (e.g. conventional vs. organic agriculture) requires complex information about factors such as changes in food consumption patterns, practices that may increase yields, use of crop residues and waste, and how much marginal land is used. Modelling consequences of conversion to less intensive agricultural systems requires a comprehensive food-system perspective rather than addressing only yield levels and potential ILUC GHG emissions. Meaningful quantification of ILUC and other indirect effects requires that we improve our knowledge about how drivers of societal change, and 
policy instruments, may affect consequences of shifting from conventional to organic food. More systemsbased research is needed on factors governing land use change, dietary transitions (conventional to organic, as well as shifts towards more plant-based diets) and reduced food waste to spare land and reduce pressures on resource use and ecosystems ${ }^{61}$. Science and policy efforts should concentrate on real-world solutions, such as increasing yields of agroecological systems and halting deforestation through improved land and forest governance ${ }^{62,63}$, rather than on quantifying ILUC factors.

\section{Conclusion}

Food production is one of the largest drivers of global environmental change and thus a major cause of exceeding planetary boundaries. Transformative redesign of agri-food systems based on agroecological principles is urgently needed, but it requires appropriate assessment tools and methods to examine the environmental performance of these systems. Currently, LCA misrepresents agroecological systems such as organic agriculture, partly because its product-based approach focuses by default on the output of provisioning services from agricultural systems, and partly because key aspects of sustainable agriculture (better soil health, lower biodiversity impacts, lower pesticide use impacts) are largely ignored. Consequently, LCA studies tend to favour intensive high-input agricultural systems that produce higher yields but provide fewer ecosystem services overall than less intensive systems. Environmental assessment of agricultural systems must adopt a broader perspective, consider negative impacts of pesticides and consider effects of agricultural practices on soil health and biodiversity. In addition, more research is needed to allow for meaningful modelling of ILUC and other indirect effects.

\section{References}

1. Willett, W. et al. Food in the Anthropocene: the EAT-Lancet Commission on healthy diets from sustainable food systems. Lancet 393 (10170), 447-492 (2019).

2. Eyhorn, J. et al. Sustainability in global agriculture driven by organic farming. Nat. Sustain. 2, 253255 (2019).

3. European Commission - Joint Research Centre. International Reference Life Cycle Data System (ILCD) Handbook - General guide for Life Cycle Assessment - Detailed Guidance. Publications Office of the European Union, Luxembourg (2010).

4. Bauman, H. \& Tillman A.M. The Hitchhiker's Guide to LCA. (Studentlitteratur AB, Lund, Sweden, 2004).

5. European Commission. The Environmental Footprint Pilots. https://ec.europa.eu/environment/eussd/smgp/ef pilots.htm

6. Clark, M. \& Tilman, D. Comparative analysis of environmental impacts of agricultural production systems, agricultural input efficiency, and food choice. Environ. Res. Lett. 12, 064016 (2017)

7. Huang, J. et al. Comparative review of multifunctionality and ecosystem services in sustainable agriculture. J. Environ. Manage. 149, 138-147 (2015). 
8. Burkhard, B., Crossman, N., Nedkov, S., Petz, K. \& Alkemade, R. Mapping and modelling ecosystem services for science, policy and practice. Ecosyst. Serv. 4, 1-3 (2013).

9. HLPE. Agroecological and Other Innovative Approaches for Sustainable Agriculture and Food Systems that Enhance Food Security and Nutrition. A report by the High Level Panel of Experts on Food Security and Nutrition of the Committee on World Food Security, Rome (2019).

10. Paull, J. From France to the world: The International Federation of Organic Agriculture Movements (IFOAM). J. Soc. Res. Policy 1(2), 93-102 (2010).

11. Basset-Mens, C., Ledgard, S. \& Boyes, M. Eco-efficiency of intensification scenarios for milk production in New Zealand. Ecol. Econ. 68, 1615-1625 (2009).

12. Haines-Young, R., Potschin-Young, M. \& Czúcz, B. 2018. Report on the Use of CICES to Identify and Characterise the Biophysical, Social and Monetary Dimensions of ES Assessments. Deliverable D4.2, EU Horizon 2020 ESMERALDA Project (2018).

13. Tuomisto, H.L., Hodge, I.D., Riordan, P. \& Macdonald, D.W. Does organic farming reduce environmental impacts? - A meta-analysis of European research. J. Environ. Manag. 112, 309-320 (2012).

14. Meier, M.S. et al. Environmental impacts of organic and conventional agricultural products - Are differences captured by life cycle assessment? J. Environ. Manag. 149, 193-207 (2015).

15. Schleenbecker, R. \& Hamm, U. Consumers' perception of organic product characteristics. A review. Appetite 71, 420-429 (2013).

16. Baranski, M. et al. Higher antioxidant and lower cadmium concentrations and lower incidence of pesticide residues in organically grown crops: a systematic literature review and meta-analyses. Brit. J. Nutr. 112, 794-811 (2014).

17. Hyland, C. Organic diet intervention significantly reduces urinary pesticide levels in U.S. children and adults. Environ. Res. 171, 568-575 (2019).

18. Sundrum, A. Organic livestock farming. A critical review. Livest. Prod. Sci. 67: 207-215 (2001).

19. Scherer, L., Tomasik, B., Rueda, O. \& Pfister, S. Framework for integrating animal welfare into life cycle sustainability assessment. Int. J. Life Cycle Assess. 23, 1476-1490 (2018).

20. IPCC. Climate Change and land. An IPCC Special Report on Climate Change, Desertification, Land Degradation, Sustainable Land Management, Food Security, and Greenhouse gas fluxes in Terrestrial Ecosystems (2019).

21. Vidal Legaz, B. et al. Soil quality, properties, and functions in life cycle assessment: an evaluation of models. J. Clean. Prod. 140, 502-515 (2017).

22. De Laurentiis, V., Secchi, M., Bos, U., Horn, R., Laurent, A. \& Sala, S. Soil quality index: Exploring options for a comprehensive assessment of land use impacts in LCA. J. Clean. Prod. 215, 63-74 (2019).

23. Lori, M., Symnaczik, S., Mäder, P., De Deyn, G. \& Gattinger, A. Organic farming enhances soil microbial abundance and activity-A meta-analysis and meta-regression. PLoS ONE 12(7): 
e0180442. (2017)

24. Dijkman, T.J., Birkved, M. \& Hauschild, M.Z. PestLCI 2.0: a second generation model for estimating emissions of pesticides from arable land in LCA. Int. J. Life Cycle Assess. 17, 973-986 (2012).

25. Silva, V. et al. Pesticide residues in European agricultural soils-A hidden reality unfolded. Sci. Total Environ. 653, 1532-1545 (2019).

26. Diaz, S. et al., Summary for Policymakers of the Global Assessment Report on Biodiversity and Ecosystem Services - unedited advance version. IPBES (2019).

27. Sánchez-Bayo, F. \& Wyckhuys, K.A.G. Worldwide decline of the entomofauna: A review of its drivers. Biol. Conserv. 232, 8-27 (2019).

28. McClelland, S.C., Arndt, C., Gordon, D.R. \& Thoma, G. Type and number of environmental impact categories used in livestock life cycle assessment: A systematic review. Livest. Sci. 209, 39-45 (2018).

29. Khatri, P. \& Jain, S. Environmental life cycle assessment of edible oils: A review of current knowledge and future research challenges. J. Clean. Prod. 152, 63-76 (2017).

30. Tuck, S.L. et al. Land-use intensity and the effects of organic farming on biodiversity: a hierarchical meta-analysis. J. Appl. Ecol. 51, 746-755 (2014).

31. Jolliet, O. et al. Global guidance on environmental life cycle impact assessment indicators: impacts of climate change, fine particulate matter formation, water consumption and land use. Int. J. Life Cycle Assess. 23, 2189-2207 (2018).

32. Chaudhary, A. \& Brooks, T.M. Land use intensity-specific global characterization factors to assess product biodiversity footprints. Environ. Sci. Technol. 52, 5094-5104.

33. Knudsen, M.T. et al. Characterization factors for land use impacts on biodiversity in life cycle assessment based on direct measures of plant species richness in European farmland in the 'Temperate Broadleaf and Mixed Forest' biome. Sci. Tot. Environ. 580, 358-366 (2017).

34. FAO. www.fao.org/faostat/en/\#data/EP/visualize, accessed on February 5, 2019.

35. Sabarwal, A., Kumar, K. \& Singh, R.P. Hazardous effects of chemical pesticides on human health cancer and other associated disorders (review). Environ. Toxicol. Phar. 63, 103-114 (2018).

36. World Health Organization. The Public Health Impacts of Chemicals: Knowns and Unknowns. WHO/FWC/PHE/EPE/16.01 (2016).

37. Avila-Vazquez, M., Difilipo, F.S., Mac Lean, B., Maturano, E. \& Etchegoyen, A. Environmental exposure to glyphosate and reproductive health impacts in agricultural population of Argentina. $J$. Environ. Prot. 9, 241-253 (2018).

38. Casado, J. et al. Screening of pesticides and veterinary drugs in small streams in the European Union by liquid chromatography high resolution mass spectrometry. Sci. Total Environ. 670, 1204-1225 (2019).

39. GEUS. Forekomst av N,N-dimethylsulfamide (DMS) og 1,2,4-triazol i de almene vandværkers boringskontrol (in Danish). (Occurrence of N, N-dimethylsulfamide (DMS) and 1,2,4-triazole during 
monitoring of drinking water). GEUS Jnr:014-250. De Nationelle Geologiske Undersøgelser fir Danmark og Grønland (2019).

40. Myers, J.P. et al. Concerns over use of glyphosate-based herbicides and risks associated with exposures: a consensus statement. Environ. Health 15, 19 (2016).

41. Goulson, D. An overview of the environmental risks posed by neonicotinoid insecticides. J. Appl. Ecol. 50, 977-987 (2013).

42. McKinlay, R., Plant, J.A., Bell, J.N.B. \& Voulvoulis, N. Endocrine disrupting pesticides: implications for risk assessment. Environ. Int. 34, 168-183 (2008).

43. Hertz-Piciotto, I. et al. Organophosphate exposures during pregnancy and child neurodevelopment: Recommendations for essential policy reforms. PLoS Medicine 15(10), e1002671 (2018).

44. Tukker, A. Risk analysis, life cycle assessment-The common challenge of dealing with the precautionary frame (based on the toxicity controversy in Sweden and the Netherlands). Risk Anal. 22(5), 821-832 (2002).

45. Zamagni, A., Guinée, J., Heijungs, R., Masoni, P. \& Raggi, A. Lights and shadows in consequential LCA. Int. J. Life Cycle Assess. 17, 904-918 (2012).

46. Yang, Y. \& Heijungs, R. On the use of different models for consequential life cycle assessment. Int. J. Life Cycle Assess. 23, 751-758 (2017).

47. Schmidt, J. H., Weidema, B. P. \& Brandão, M. A framework for modelling indirect land use changes in life cycle assessment. J. Clean. Prod. 99, 230-238 (2015).

48. Mason Earles, J. \& Halog, A. Consequential life cycle assessment: a review. Int. J. Life Cycle Assess. 16, 445-453 (2011).

49. Finkbeiner, M., 2014. Indirect land use change - Help beyond the hype? Biomass Bioenerg. 62, 218 221 (2014).

50. Parra Paitan, C \& Verburg, P.H. Methods to Assess the Impacts and Indirect Land Use Change Caused by Telecoupled Agricultural Supply Chains: A Review. Sustainability 11, 1162 (2019).

51. Smith, L. G., Kirk, G. J., Jones, P. J. \& Williams, A. G. The greenhouse gas impacts of converting food production in England and Wales to organic methods. Nat. Comm. 10(1), 1-10 (2019).

52. Searchinger, T.D., Wirsenius, S., Beringer, T. \& Dumas, P. Assessing the efficiency of changes in land use for mitigating climate change. Nature 564: 249-253 (2018).

53. Fischer, J. et al. Land sparing versus land sharing: Moving forward. Conserv. Lett. 7(3), 149-157 (2014).

54. Barretto, A., Berndes, G., Sparovek, G. \& Wirsenius, S. Agricultural intensification in Brazil and its effects on land use patterns: An analysis of the 1975-2006 period. Global Change Biol. 19(6), 18041815 (2013)

55. Baudry, J. et al. Dietary intakes and diet quality according to levels of organic food consumption by French adults: cross-sectional findings from the NutriNet-Santé Cohort Study. Public Health Nutr. 20, 638-648 (2017). 
56. Font Vivanco, D. \& van der Voet, E. The rebound effect through industrial ecology's eyes: a review of LCA-based studies. Int. J. Life Cycle Assess. 19, 1933-1947 (2014).

57. Kremen, C. \& Miles, A. Ecosystem services in biologically diversified versus conventional farming systems: benefits, externalities, and trade-offs. Ecol. Soc. 17, 40 (2012).

58. De Laurentiis, V., et al. Soil quality index: Exploring options for a comprehensive assessment of land use impacts in LCA. J. Clean. Prod. 215, 63-74 (2019).

59. Sirami, C. et al. Increasing crop heterogeneity enhances multitrophic diversity across agricultural regions. Proc. Natl. Acad. Sci. U.S.A. 116(33), 16442-16447 (2019).

60. Alejandre, E.M., van Bodegom, P.M. \& Guinée, J.B. Towards an optimal coverage of ecosystem services in LCA. J. Clean. Prod. 231, 714-722 (2019).

61. Muller, A. et al. Strategies for feeding the world more sustainably with organic agriculture. Nat. Comm. 38, 1290 (2017).

62. Lambin, E.F. \& Meyfroidt, P. Global land use change, economic globalization, and the looming land scarcity. P. Natl. Acad. Sci. USA 108(9), 3465-3472 (2011).

63. Byerlee, D., Stevenson, J. \& Villoria, N. Does intensification slow crop land expansion or encourage deforestation? Global Food Secur-Agr. 3, 92-98 (2014).

\section{Acknowledgements}

The authors thank Göran Berndes, Michael Corson, Roland Clift and four anonymous reviewers for helpful comments on the manuscript. We thank Sylvaine Bitteur and Monique Delabuis for help with graphics and Jacques Baudry and Valérie Viaud for landscape photographs. Thanks to Hubert van Nispen van Sevenaer for inspiration.

\section{Author contributions}

H.v.d.W. and M.T.K. had the initial idea; H.v.d.W., M.T.K. and C.C. contributed ideas and wrote the paper.

\section{Competing interests}

The authors declare no competing interests.

\section{Additional information}

Correspondence should be addressed to H.v.d.W. 


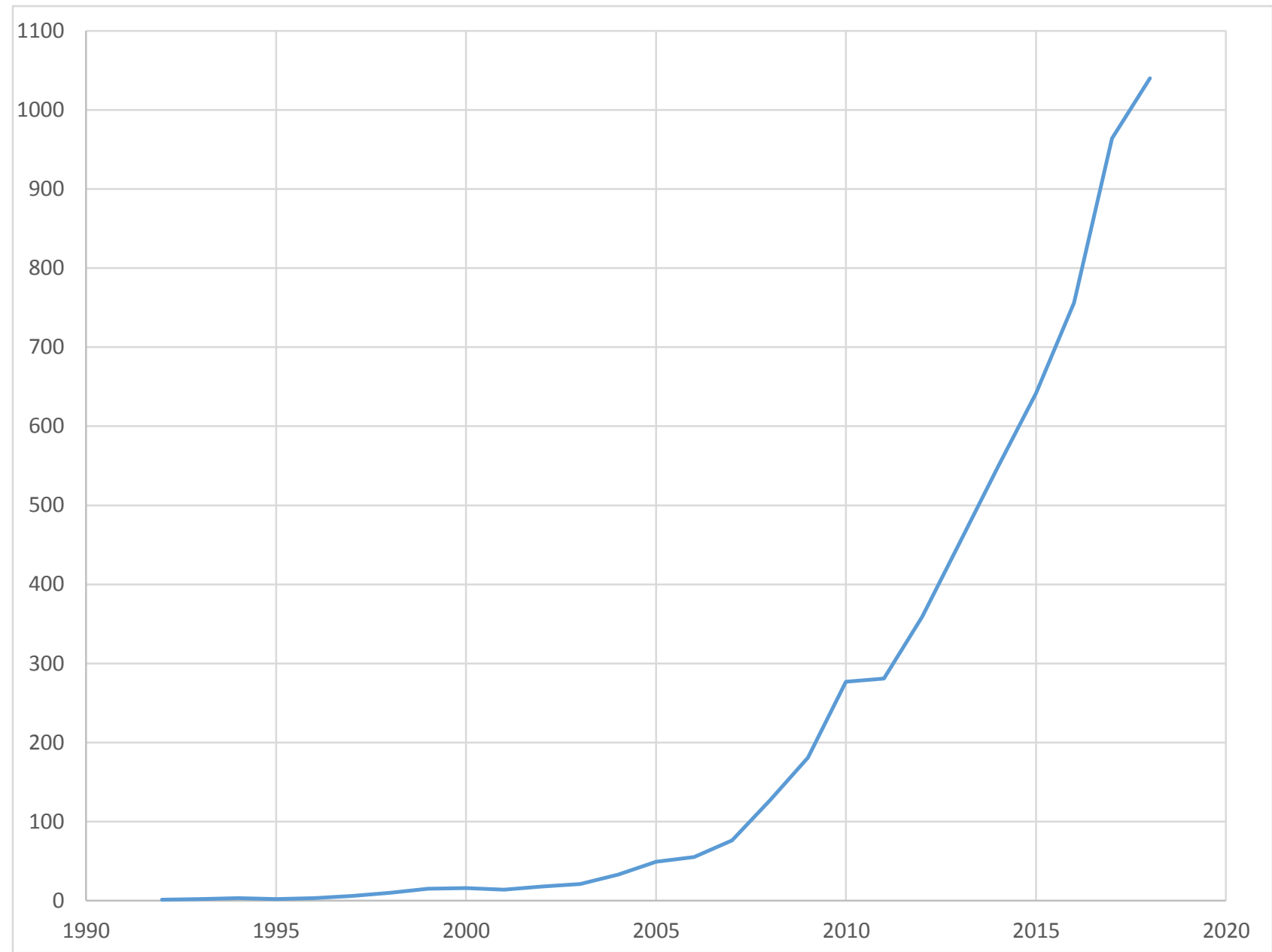

588 Figure 1. Annual number of peer-reviewed English-language articles published from 1990-2018 using life 589 cycle assessment to assess agricultural and food systems (total $=5954$ ). 


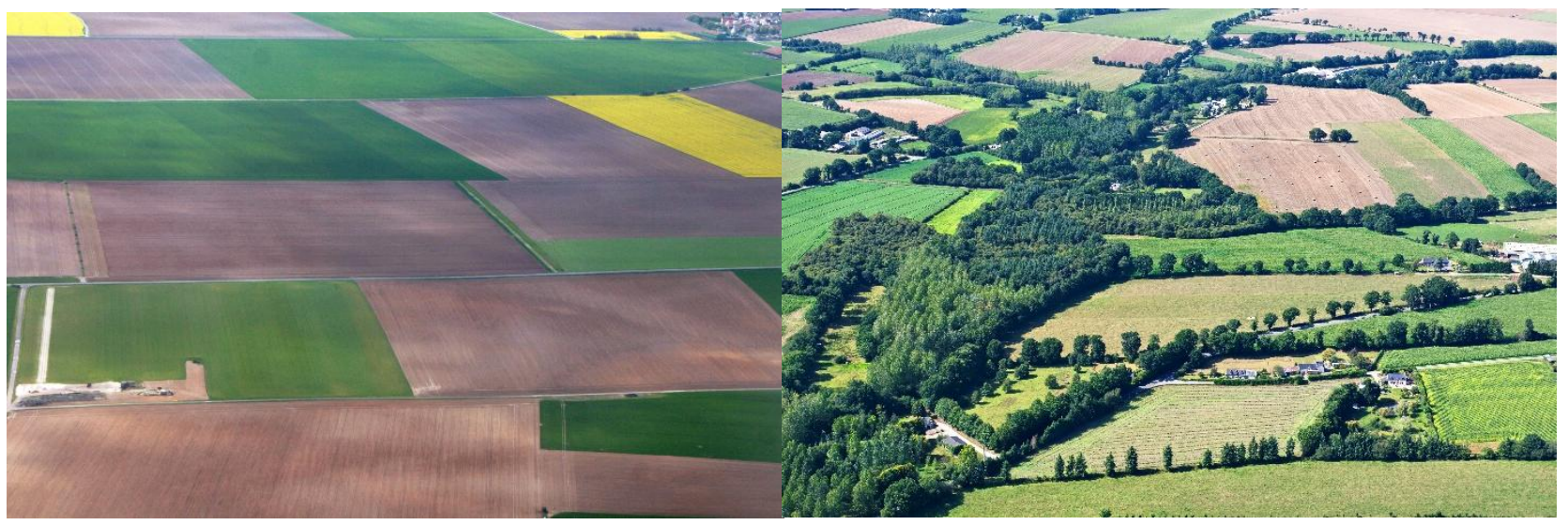

593 Fig 2. Agricultural systems and landscapes can be classified along a continuum from high-input intensive to 594 agroecological. Photo a) shows an example of high-input intensive agriculture, aiming for high yields of a 595 few crop species, with large fields and no semi-natural habitats. Photo b) shows an example of 596 agroecological agriculture, supplying a range of ecosystem services not limited to crop and animal 597 production, relying on biodiversity and crop and animal diversity instead of external inputs, and integrating 598 plant and animal production, with smaller fields and presence of semi-natural habitats. Current LCA 599 methodology and studies tend to favour high-input intensive agricultural systems and misrepresent less 600 intensive agroecological systems such as organic agriculture. 


\section{Life cycle assessment and Ecosystem services conceptual frameworks}
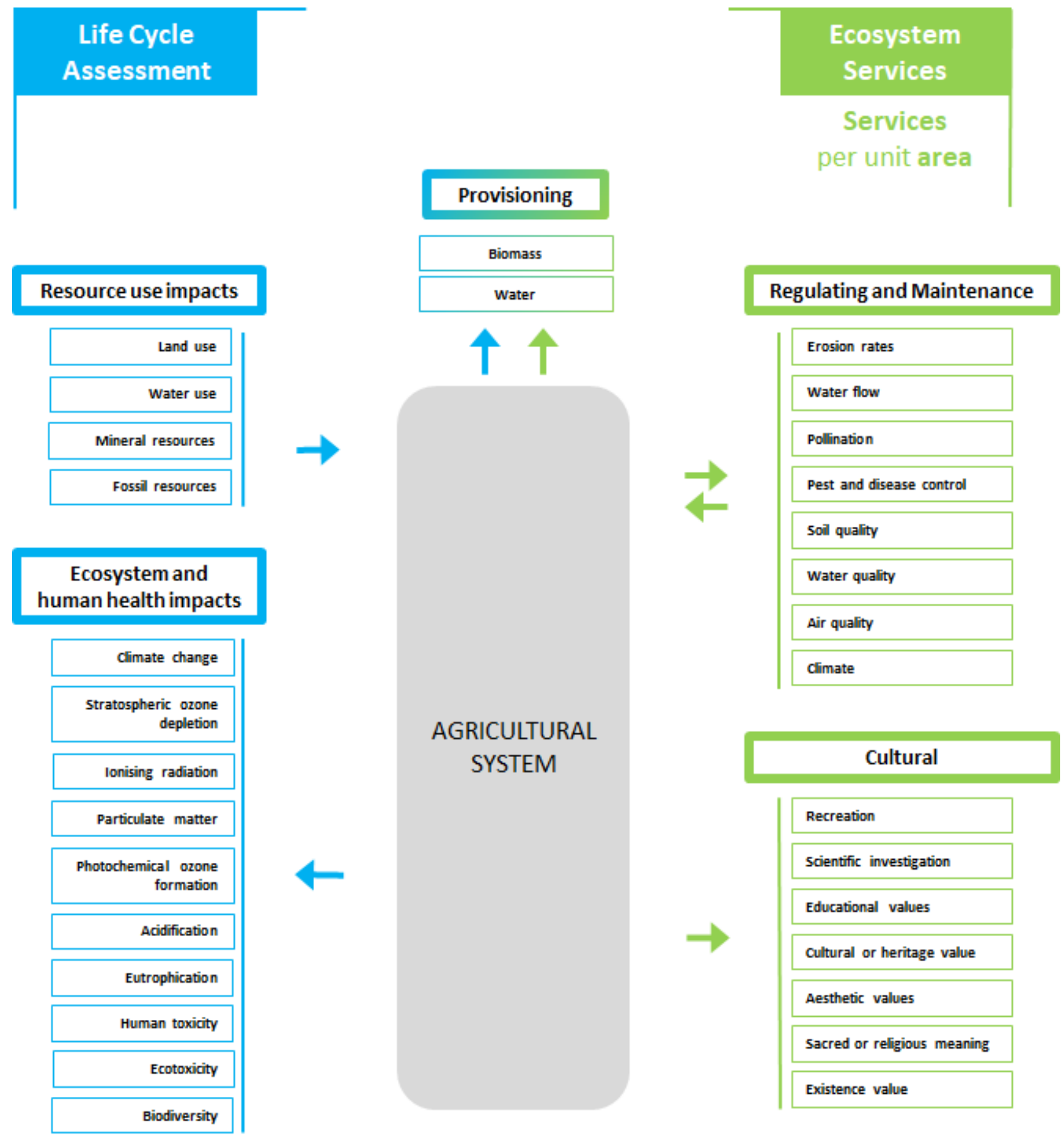

604 Figure 3. Life cycle assessment (LCA, in blue) and ecosystem services (in green) conceptual frameworks. 605 The central panel represents an agricultural system, i.e. a farm or farming region, including semi-natural 606 habitats. LCA assesses environmental impacts of the system by considering both on-site and off-site 607 (associated with inputs) resource use, pollutant emissions and land use. Resource use, ecosystem and human 608 health impacts are quantified using a set of indicators expressed per unit of product (e.g. $\mathrm{kg}$ of milk 609 produced). Ecosystem services assess provisioning, regulating and maintenance, and cultural ecosystem 
610 services provided by the structure and functions of the system. Other ecosystems supply the system with 611 additional regulating and maintenance ecosystem services. Ecosystem services are quantified using a set of 612 indicators expressed per unit area, e.g. ha of land occupied. LCA and ecosystem services have common 613 ground, e.g. emissions and sequestration of greenhouse gases are considered in the climate change impact 614 (LCA) and in the climate regulating service (ecosystem services). This comparison also reveals "blind spots": 615 LCA does not consider ecosystem services other than provisioning, whereas ecosystem services do not 616 consider resource use and effects of inputs used in the system.

617 
- Assess land degradation, biodiversity and pesticide effects, and do so using the best methods available.

- Use both product-based and area-based functional units.

- Supplement LCA with other frameworks, such as that for ecosystem services, for more comprehensive analysis of functions of agricultural systems.

- Consider farm practices and local soil, climate and ecosystem characteristics in detail.

- When studying indirect effects of transition to agroecological systems, do not consider only indirect land use change.

- If indirect effects are included, results should be interpreted very carefully because of the high uncertainty. 